\title{
EFL In-service Yemeni Teachers' Perceptions and Perspectives on the Importance of Teaching Stress and Intonation as Supra-segmental Features of Speech and Sound attributes to the Process of Comprehension: A Survey-Study
}

\author{
Rafiq Al-Shamiry \\ Associate professor, Dept. of English Language, Faculty of Arts \\ The University of IBB, IBB, Yemen \\ Email: rafiqshamiry@gmail.com
}

Ahmed M. S. Alduais (Corresponding author)

Independent researcher, Riyadh, Saudi Arabia

Tel: 966-55-136-7208_Email: ibnalduais@yahoo.com

Received: May 3, 2013 Accepted: June 6, 2013 Published: July 20, 2013

doi:10.5296/ijssr.v1i1.3631ＵRL: http://dx.doi.org/10.5296/ijssr.v1i1.3631

\begin{abstract}
Purposes: To obtain the EFL in-service Yemeni teachers' perceptions and perspectives on the importance of teaching stress and intonation as supra-segmental features of speech and sound-attributes to the process of comprehension. Methods: 40 EFL teachers who were identified as in-service teachers in both public and private schools at IBB city, Yemen (20 Arts' graduates and 20 Education's graduates, both males and females) participated in this survey-study. A researcher-made questionnaire consisting of 20 items - aiming at achieving the above stated objective was distributed to the participants. Results: The 17th version of SPSS, descriptive statistics, mainly percentages and frequency tools were used to analyse the collected data. The statistical data indicated that a large number of the in-service teachers are incompetent in the supra-segmental features of speech, yet demonstrated negative attitudes
\end{abstract}


towards the importance of using applying such features. Though there is an attempt to communicate in English language, there is no clear consideration for the use of these features of speech. Syllabus' update, motivation and teachers' fluency, and teachers overall qualification are the the responsible factors behind the failure of practice and appropriate use of these features. Educational system, social situation, major differences between the two phonological systems of the Arabic and English languages, and difficulty of these features of speech are the discouraging factors respectively from the teachers' perspective. Developing teaching methods, laboratories, and frequent evaluation were the proposed encouraging factors from the teachers' perspective. Conclusions: The study is concluded with that a large number of the in-service school's teachers are incompetent in terms of supra-segmental features of speech due to focus on other language elements other than communication. Most of the teachers are not fluent and this supports their tendency to ignore applying yet showing the importance of these features to their learners - an ability which they themselves are not competent in.

Keywords: In-service Yemeni teachers, Stress and intonation, Supra-segmental features of speech

\section{Introduction}

It is agreed by most of the world linguists that learners of whatever language it is, from whatever country they are-are inevitably going to face many difficulties when acquiring/learning that particular language. However, any enquiries such as to what extent these difficulties are going to cause problems to foreign learners, and again to what extent these difficulties can be overcome if the learners are going to follow the suggested remedies by expert linguists and researchers.

That is to say, some of the linguists say that there are some linguistic matters which are very different and at the same time very difficult for a non-native learner to overcome perfectly, especially in the sense of phonology and phonetics. So, it is sometimes seemly impossible to master a foreign language perfectly. Some others say that whatever difficulties a learner might face or however a language is, a learner can overcome if he/she is serious about the thing that he/she is doing.

Yet, it is also added by the same party that any language will inevitably have some linguistic items that seem to beginners very difficult or sometimes impossible to overcome but in fact such difficulties can be overcome by some certain tested activities. For instance, there are many learners of English who are of course non-native speakers but they speak English as fluent as native speakers.

This actually indicates that they do communicate successfully and apply the main features of speaking skill but are not exactly as the native speakers. Thus it can be concluded that not all learners' problems are to be attributed directly to only the linguistic difficulties and to neglect simply all other personal, social, and political factors that can be approved sometimes as more negatively effective than do the linguistic ones.

Put it another way, since the problem is that most of the students at the faculties of Arts and 
Education, and teachers at both private and public schools and institutes in IBB governorate are not keenly competent in English stress and intonation and cannot, therefore communicate successfully.

In effect, this study aimed as answering the following questions from the Yemeni in-service teachers' perspective(s):

(1) Are the Yemeni learners of English incompetent in English stress and intonation because they are not aware of their importance and functions?

(2) Are they incompetent in English stress and intonation because these features are chiefly neglected in the syllabi at schools as well as at departments of English?

(3) How often do they try to apply them, when they attempt to communicate in English?

(4) Who is the first responsible for the students are being unable to communicate successfully?

(5) What are the various factors that may discourage the students to use/practice stress and intonation?

(6) What are the various factors that can encourage students to use stress and intonation when they attempt to communicate in English?

\section{Method}

\subsection{Participants}

The population of this study are In-service Yemeni teachers who graduated from English Language Departments, Faculties of Arts and Education, the University of IBB, IBB, Yemen, and who have been teaching English in both private and public schools. The in-service teachers teach English in the school from the 1st preparatory level till the 3rd secondary level in the public schools and from the kindergarten level to the 3rd secondary school level in the private schools.

The researchers followed random sampling method where 40 teachers, both females and males from the two faculties participated in this study. Tables (1 and 2) show the distribution and characteristics of the subjects of this study.

Table 1. Distribution of the subjects

\begin{tabular}{llllll}
\hline \multicolumn{4}{l}{ Faculty of Arts: English Dept. } & \multicolumn{4}{l}{ Faculty of Education: English Dept. } \\
\hline School type & Number & Gender & School type & Number & Gender \\
Public & 10 & F \& M & Public & 10 & F \& M \\
Private & 10 & F \& M & Private & 10 & F \& M \\
Sub-total & 20 & & Sub-total & 20 & \\
Total & 40 & & & & \\
\hline
\end{tabular}


Table 2. Characteristics of subjects

\begin{tabular}{ll}
\hline Age range & $25-35$ \\
\hline Mother tongue language & Arabic Language \\
Dialect & Yemeni Arabic Language \\
Ethnicity & Islam \\
Other languages & English (ESL and EFL use), basic French for some \\
Gender & Female and male (single and married) \\
Nationality & Yemenis \\
Specific characteristic & Be either formally employed by the Ministry of Education or \\
& hold a formal contract in the case of private schools. \\
\hline
\end{tabular}

The setting of the study was the University of IBB, IBB city, Yemen. The study was conducted between the period of early January 2007 and late May 2007. The participating teachers are either graduates of the Department of English Language \& Literature, Faculty of Arts which is located in the main campus of the University of IBB, IBB city, or of the Department of English, Faculty of Education which is located in Alnaderah district. More importantly, they were teachers in the following schools: Arwa Girls School (public), Alrwad Private School for Boys and Girls, Mujama'a Alsa'aeed (public, for girls), Alnahdah school (public, for boys), and Alresalah Private School (for boys and girls). It should be noted that all the above mentioned schools are located in the main city of IBB governorate.

The results of this study are and were prepared to be generalized for those who did not participate and for all other In-service Yemeni teachers of the English Language. The researchers claim that such results of 40 subjects would be really sufficient to get a general idea about the teachers' perspectives in regard to such investigated issue.

\subsection{Measures}

A researcher-made questionnaire that includes 20 items was used as a measuring tool in this study. The 20 items of the tool were divided into six groups wherein each group represents a certain question of the six questions raised in the paper. The following table shows the division of such items into six groups.

Table 3. Grouping the questionnaire items into six groups

\begin{tabular}{ll}
\hline Theme & Items \\
\hline 1. Teachers' attitudes & $1-2$ \\
2. Teachers' competence and awareness of the functions of stress and intonation & $3-6$ \\
3. Applying the supra-segmental features of speech & $7-9$ \\
4. Responsible person/ factor for the problem & $10-13$ \\
5. Discouraging factors & $14-17$ \\
6. Proposed encouraging factors & $18-20$ \\
\hline
\end{tabular}




\section{Macrothink}

Regarding the usability of the researcher-made questionnaire, it was achieved through testing both validity and reliability features. In terms of validity, two types of the construct validity were achieved, namely face and content validities. In the case of face validity, it was achieved by handing the tool to a professor of English Language from the University of IBB who stated and decided subjectively that such tool seeks for answers regarding the use of stress and intonation and the reasons for the neglect of their use by ESL learners. This indicated that such tool is valid in terms of face validity. As for content validity, it was achieved by dividing the tool's items into 6 groups and/or themes (look at table 3 above). This division made it easy to decide on any either irrelevant or unrelated items to the investigated topic.

For reliability, the collected responses were rated twice to achieve inter-rater reliability. The double rating of the collected responses indicated that both collected data and calculated results are highly consistent.

\subsection{Design}

A survey-study approach was followed in this study where in a balanced distribution representing all targeted population was highly considered. The chart below shows the methodological design of this study (it can be read either up-down or down-up).

\section{Chart 1: Study design}

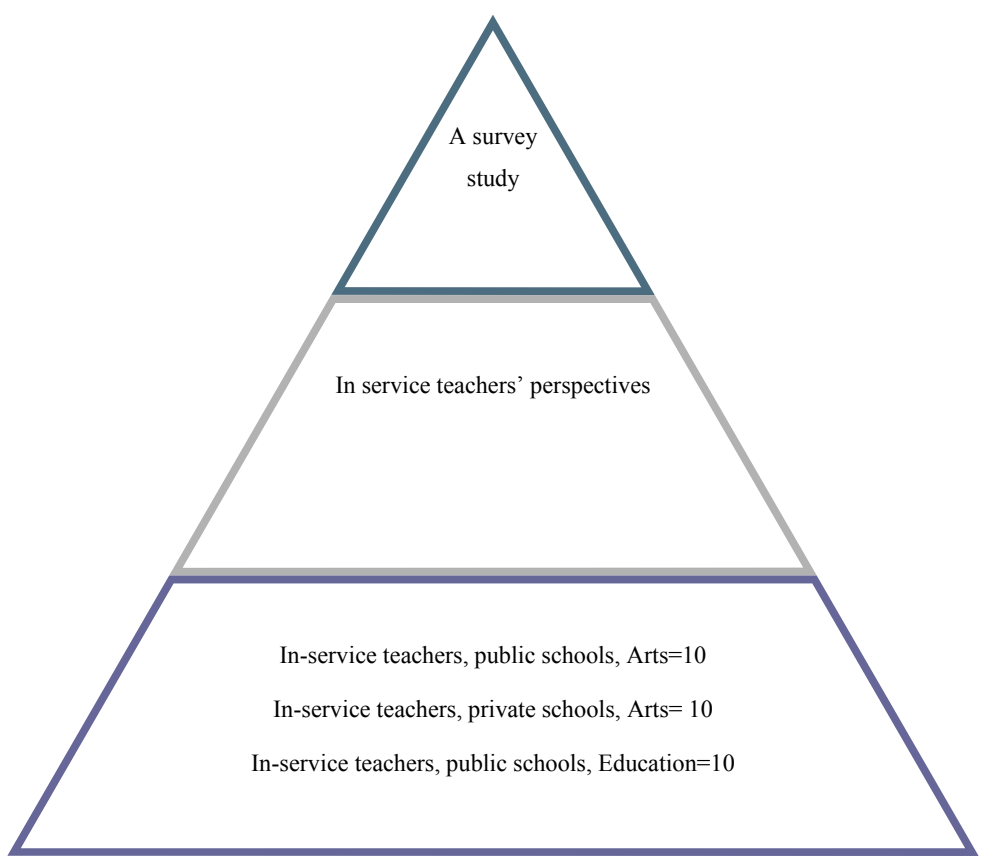




\subsection{Procedure}

Data-collection: the data of this study was collected using a researcher-made questionnaire.

Authenticity: a consent statement was included within the questionnaire stating the high authenticity of the collected data and using it only for research purposes. The participants were given the opportunity not to participate in the research unless they were willing to do so.

Questionnaire distribution: the questionnaire was distributed to the in-service teachers of the above mentioned private and public schools by the co-researcher.

Time and environment: the teachers were given the chance to keep the questionnaire with them and hand it back by the end of the week in order to avoid obtaining misleading data by the rush of time. The estimated time for filling each questionnaire is about 10-15 minutes.

Process performance: a teacher reads each item (20 items) and chooses any of the scales (totally agree, totally disagree, partially agree, and partially disagree), except for the items 7 , 8 and 9, there are five scales (always, often, sometimes, rarely, and never). In the first part, the teacher provides data regarding type of faulty (Arts or Education).

Scoring: the value of each answer is scored and counted simply in terms of frequency and percentage according to the format of stating each item (either negation or affirmation).

Preliminary analysis steps: the results are counted statistically in terms of percentages in most of the items and in terms of frequency as in items 7,8 , and 9.

\section{Results}

It has been mentioned at the end of the introduction section that the present study attempts answering the following six questions:

(1) Are the Yemeni learners of English incompetent in English stress and intonation because they are not aware of their importance and functions?

(2) Are they incompetent in English stress and intonation because these features are chiefly neglected at schools as well as at departments of English?

(3) How often do they try to apply them, when they attempt to communicate in English?

(4) Who is the first responsible for the students are not being able to communicate successfully?

(5) What are the various factors that may discourage the students to use/practice stress and intonation?

(6) What are the various factors that can encourage students to use stress and intonation when they attempt to communicate in English?

Using the 17th version of the Statistical Package for Social Sciences (SPSS), descriptive statistics, mainly (frequency and percentages tools), the following figures (1-12) [the figure to the left represents the answers of the teachers of the Faculty of Education and the figure to 
the right represents the answers of the teachers of the Faculty of Arts] answer the above questions statistically, yet with superficial interpretations.

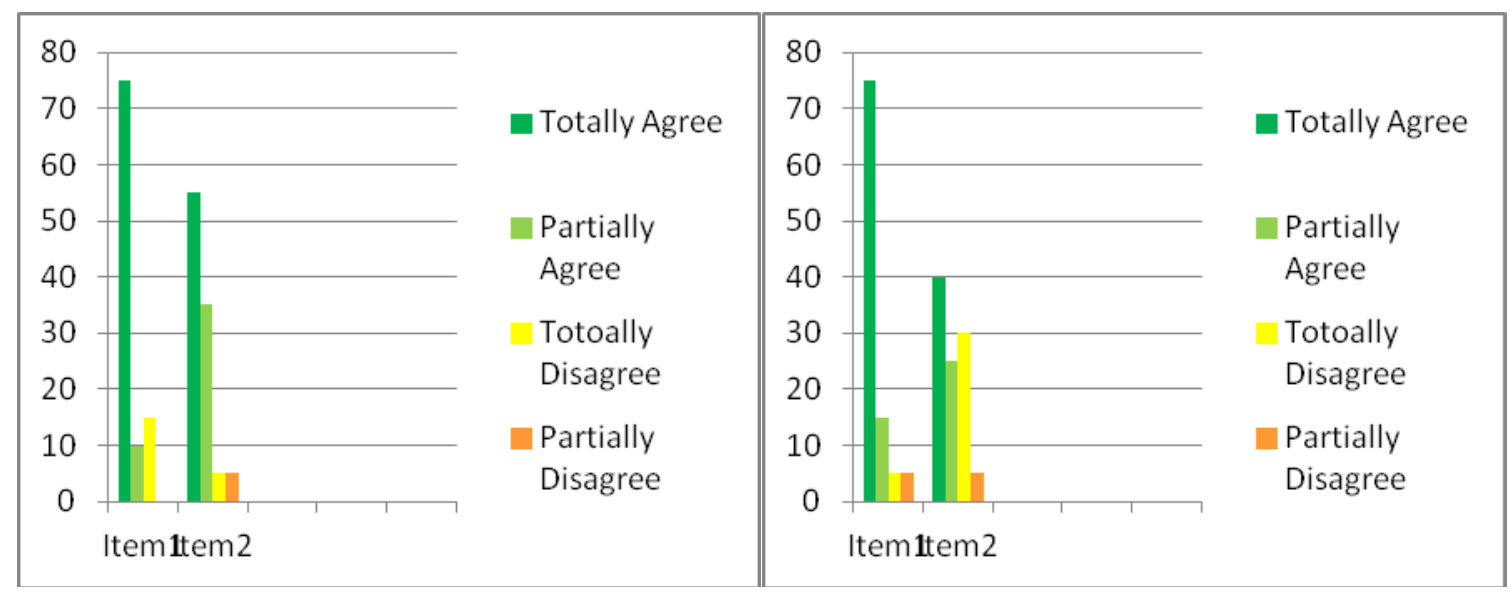

Figures 1 and 2. Teachers' attitudes towards the importance of improving speaking skill

Figures 1 and 2 show the results of the questions which are asked to demonstrate the teachers' attitudes towards the importance of improving speaking skill and studying it along with the other skills as interconnected ones. Yet each of the questions is different but alike. That is to say, while the first one is to draw the teachers' information from their own experience as specialist students of English, the other one is to draw some information from them as teachers of English language, a language which is different from their native tongue language, yet are teaching it. The results report that over 60 percent of the teachers only who agreed totally that improving the speaking skill can make a teacher more successful and effective on his/her professional life. Surprisingly, less than 50 percent of the teachers especially from the Faculty of Arts (40 percent) who agreed totally to the same idea, for the students. Thus, it proves that students as well as teachers of the English departments have amongst them a large number who are incompetent in the productive skills.

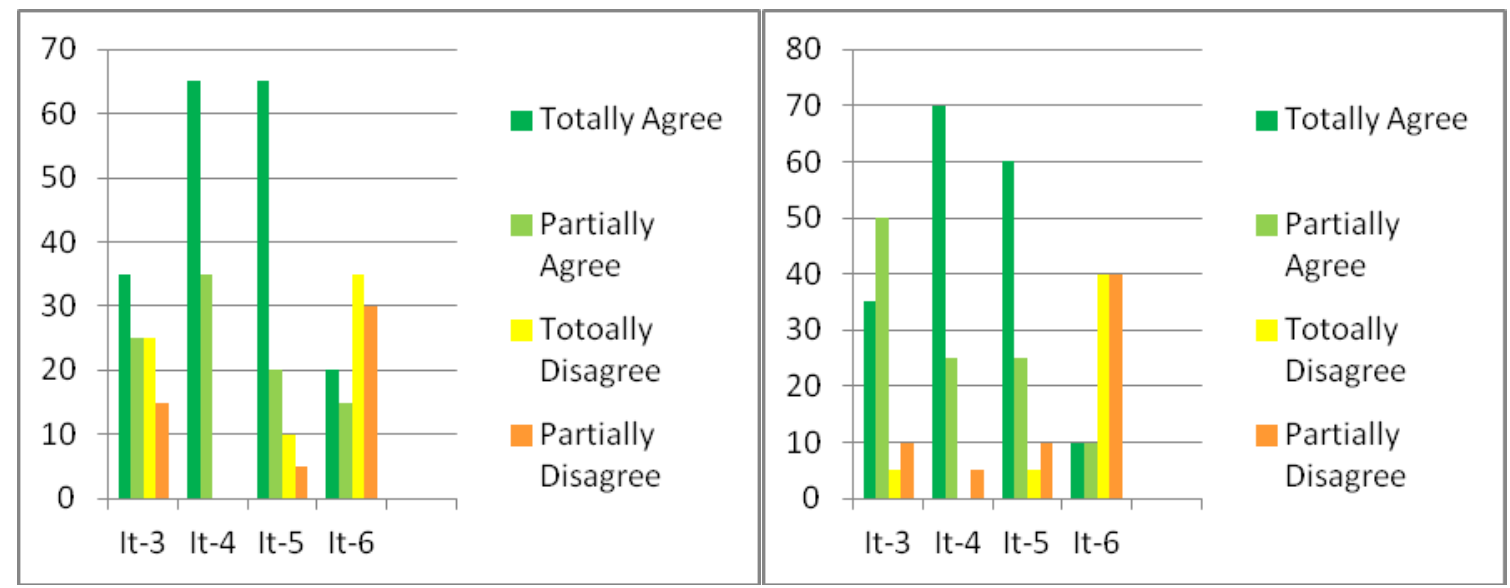

Figures 3 and 4. Teachers' awareness of the functions and importance of supra-segmental features of speech 


\section{Macrothink}

Figures 3 and 4 illustrate the responses of a number of the questions which are meant to evaluate the teachers' competence and awareness in the functions and the importance of using/applying the main features of speaking skill. More importantly, to prove the idea that because they are studying nearly everything theoretically, so most of them are incompetent in the productive skills. Admittedly, not more than 45 percent of the involved teachers (which is less than half of them) who proved as aware of the functions of stress and intonation. That is to say, more than half of the involved teachers are not aware of these functions. Certainly, it indicates that they are not applying/practicing what they have studied theoretically.

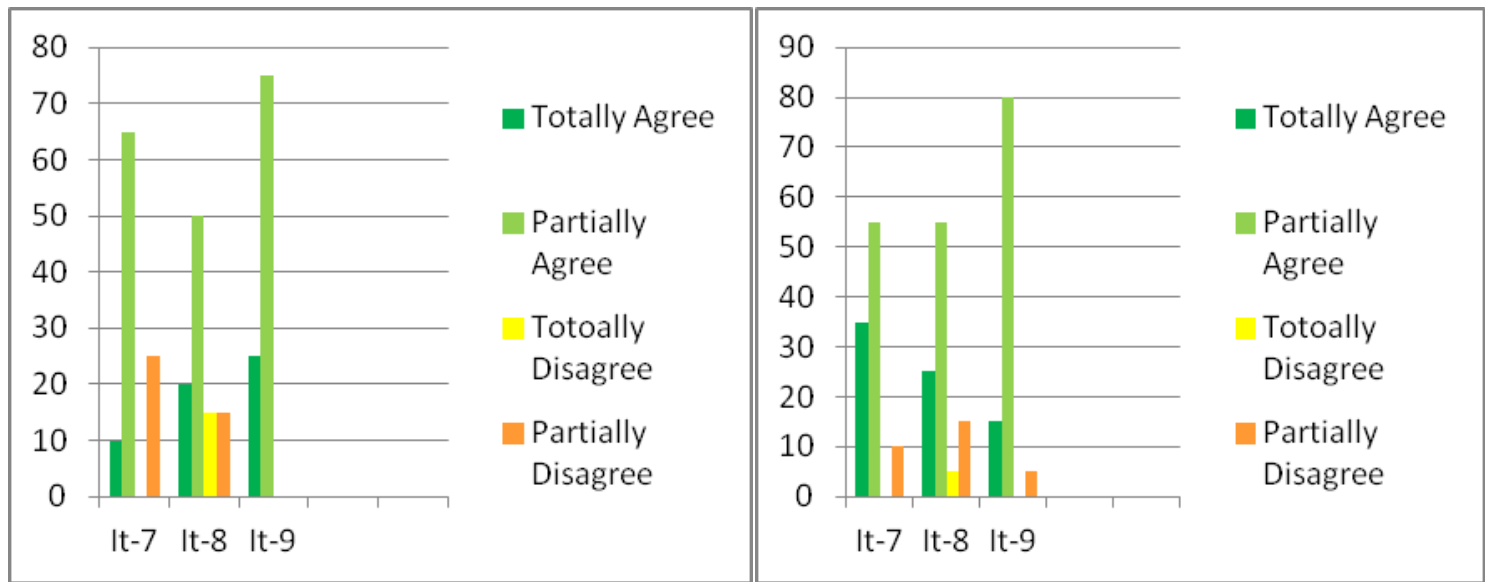

Figures 5 and 6. Teachers' effort and time for applying the supra-segmental features of speech while communicating in English

Figures 5 and 6 show the responses of a number of the questions which are asked to demonstrate clearly the amount of time during which the teachers are trying to apply the main features of speaking skill when they attempt to communicate in English in whatever situation of their lives. Yet, such questions are made to prove analytically that both teachers and students are attempting to communicate in English but they are not doing the same efforts for applying English stress and intonation. Hence, the results report that they are to a great extent try to communicate in English but to some extent try to communicate in English and at the meanwhile apply the main features of the speaking skill. Put it another way, the students as well as teachers do always try to communicate in English but they may rarely do apply the main features of the speaking skill when they always try to communicate in English. 


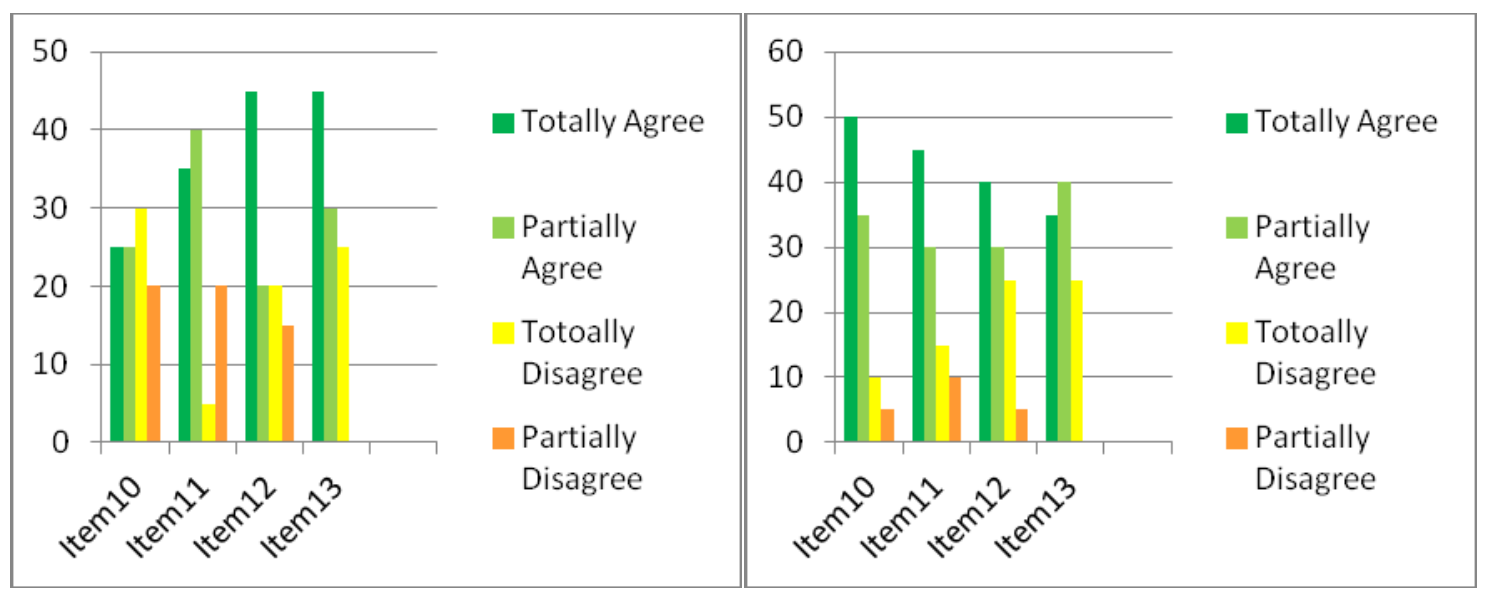

Figures 7 and 8 . Teachers' perspectives towards the main reasons(s) for the students unable to communicate successfully in English in terms of supra-segmental features of speech

Figures 7 and 8 declare the results of the number of the questions which are considerably important to the researchers. That is to say, they are an attempt to enumerate the responsible person/factor for most of the students are not being to pronounce most of the words they had learnt at secondary school and more than that not being able to communicate successfully. So the results maintain that the highest percentage of the respondents agreed totally to the idea that the syllabuses are not updated regularly is the first responsible factor for this problem. Lack of Motivation and teachers are not good speakers of English, they consider equally as the second responsible factor. As the last one they consider that teachers are sometimes not qualified at all.

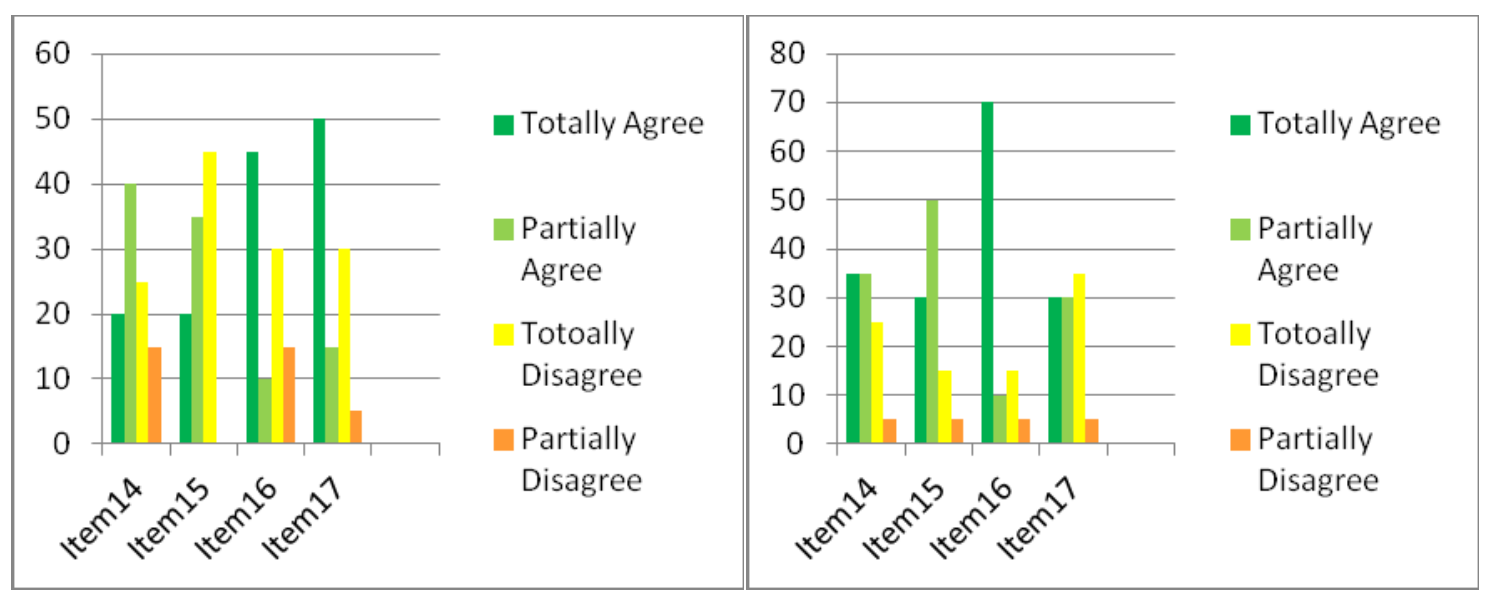

Figures 9 and 10. Discouraging factors for learners and teachers to apply and use appropriately the supra-segmental features of speech

Figures 9 and 10 illustrate clearly the results of the questions which are asked to determine from among the above mentioned factors the number one discouraging factor for the students as well as teachers to apply the main features of speaking skill when they attempt to communicate in English. However, the results report that the current educational system is 
the number one discouraging factor. The social situation, they say is the number two discouraging factor and the third one is that English and Arabic are not cognate languages. The number four discouraging factor is the high difficulties of English stress and intonation.

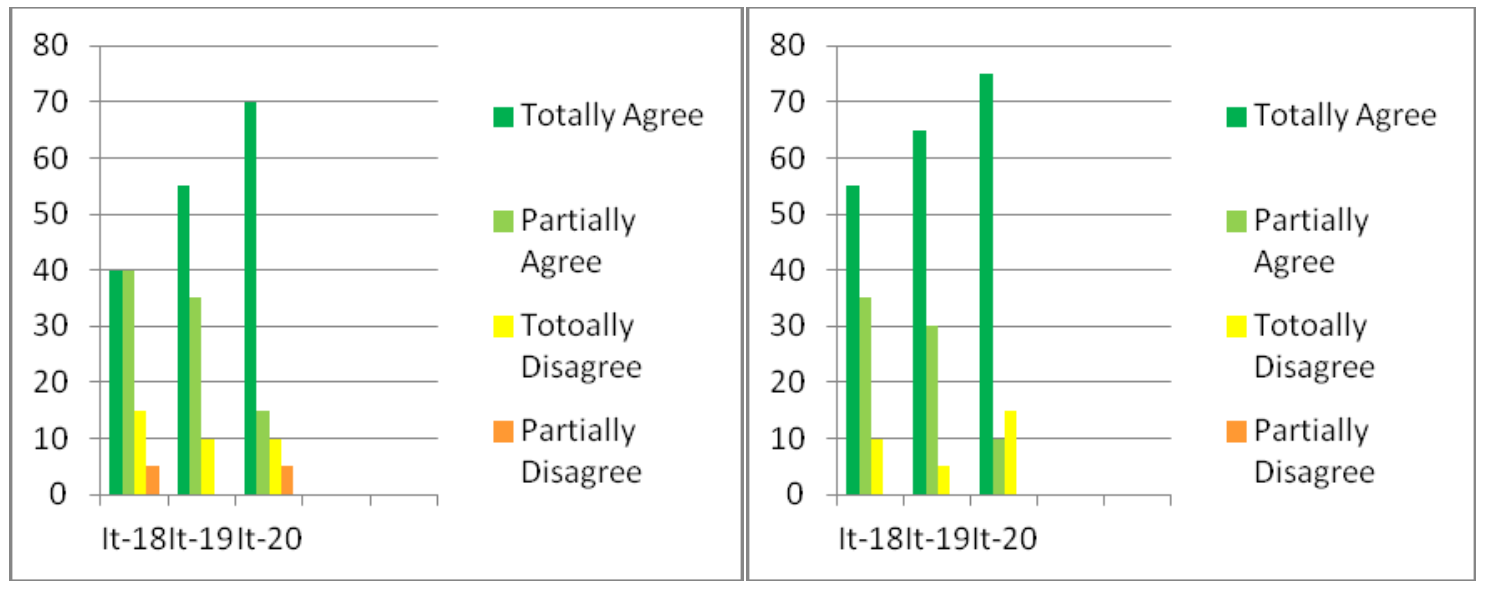

Figures 11 and 12. Encouraging factors to apply and use the supra-segmental features of speech when communicating in English

Figures 11 and 12 show the results of the questions which are asked to infer the fact that frequent evaluation is the number one encouraging factor for the students and teachers to use/practice the main features of speaking skill. Moreover, to verify some other ideas including that of English laboratories in the university and developing the methods of teaching can also to some extent encourage the students and teachers to improve their productive skills. However, the results show that developing the methods of teaching as the number one encouraging factor. English laboratories, to be made available in the university, they maintain as the number two, and frequent evaluation as the number three encouraging factor.

\section{Discussion}

It has been shown above statistically that the basic causes for the incompetency and the lack of the use of supra-segmental features of speech can be traced to six reasons from the in-service Yemeni teachers' perspectives: the chiefly neglect of practicing these factors at schools as well as at the English departments, unawareness of the functions and importance of these features, focusing to great extent on the theoretical side of English learning and neglecting/avoiding the practical side, irresponsibility, some discouraging factors, and some encouraging factors. The below given discussion will present such reasons and/or causes argumentatively.

To start with the first cause of the students' and teachers' incompetence in using English stress and intonation when they speak in English in particular and when they study the other skills of English in general. However, it appears that there are only less than half of the teachers who agreed totally to the ideas asked about neglecting the main features of speaking skill. For instance, the statistical results show analytically the following points: 
(1) Over 50 percent of the teachers agreed totally that a specialist learner of English must improve his/her speaking skill;

(2) Over 50 percent agreed also totally that most of the students did not listen to the tapes given with English courses in both preparatory and secondary schools;

(3) Less than 50 percent agreed totally that it is necessary for a learner to peak as fluent as a native speaker;

(4) About 50 percent agreed totally to the importance of understanding all the skills perfectly;

(5) Again over 50 percent agreed totally to the importance of the practicing the main features of speaking skill;

(6) Over 70 percent of the involved teachers agreed totally to the fact that speaking skill can make a teacher more successful in his/her professional life.

Thus, this proves that one of the basic causes of the students' teachers' incompetence can be traced to the event of the neglect of practicing stress and intonation at schools and at the departments of English as well at college level.

To make it clear, according to the results one can hardly find over 60 percent of the teachers who have totally agreed to each of the above mentioned points. That is to say, there are about half of the whole involved respondents who responded negatively, because such features are not taught at schools, a thing which reflects that teachers themselves are not using these features when they teach. For instance, over 70 percent of the teachers stated that improving speaking skill can make a teacher more successful in his/her professional life. Surprisingly, less than 50 percent of the same respondents who agreed totally that the same idea can be applied to the students.

Therefore, such contradictive responses, suggest to a great extent that neither most of the students nor most of the teachers are highly competent in English stress and intonation and also in all other practical skills, because these features are chiefly neglected at schools and at the departments of English as well.

The next reason that can be traced for the students' and teachers' incompetence from the teachers' perspective is the unawareness of the main functions of the main features of speaking skill. The following example illustrates clearly this statement. The results of the questionnaire declare that only about half of the respondents who agreed totally that they are aware of the main functions of the main features of speaking skill but likely not able to communicate successfully. On the other hand, there are over 45 percent of the same respondents who negatively responded. Put it simply, among those over 45 percent from both students and teachers who are not sure about their answers which analytically proves that $\mathrm{s} / \mathrm{he}$ might be aware of the functions of these factors but $\mathrm{s} /$ he might certainly forget because they (teachers and students) are not using/ applying them when they communicate in English. Yet, others either totally or partially disagreed, a thing which indicates to a great extent that they are not aware of the main functions of the mentioned factors. More than that, it indicates that 
teachers do probably not care for words' pronunciation at schools.

One can notice that over 70 percent of the teachers responded positively, yet in some other responses, the number decreases to less than 55 percent. Needless to say, it was expected that just a very little number of the teachers who will appear not aware of the functions of these features or respond negatively. Nevertheless, it becomes again as an evident that there is a large number of the students and teachers who are not aware of the functions of practicing English stress and intonation. In effect, it can $b$ stated that there are accentual, attitudinal, morphological, syntactical, and also semantic functions for stress and intonation which are not known to most of the students and teachers too.

Another reason for the students' and teachers' incompetence in English stress and intonation in particular, and in using the language practically in general is neglecting the process of practicing the main features of speaking skill. For instance, the results of the questionnaire report clearly that about 60-65 percent of the respondents who try often to apply these features when they attempt to communicate in English. Yet, the results state also that they are trying to apply these features inside the class more than outside the class. Thus, it indicates that the over majority of both teachers and students do not always try to apply these features.

However, it can be traced that the students study stress and intonation theoretically rather than practically; a thing which negatively affects the process of communicating successfully. To make it clear, the researchers arose carefully the question that how often do the students and teachers try to apply the main features when they communicate in English. Paying attention to the word "try", which indicates indirectly applying these features but only trying; in spite of that, only about quarter of the teachers who are always trying to apply these features. Needles to say, if the question was to be asked directly, the results were going to be worse than these reported here.

One more reason of the students and teachers' incompetence is neglecting/avoiding using/applying stress and intonation by most of the students during the period of study at the university and by most of the teachers during the period of teaching at schools. Put it another way, it is observed that most of the students who graduated from secondary schools and have joined the departments of English are mispronouncing nearly all the words they had learnt at the school. Above all, it is claimed by most of the teachers that they as teachers are not the number one responsible for the students do graduate with mispronouncing words.

Once again, some other teachers think that social situation and the difficulty of communicating with other people as most of them including those of the English departments may wish to communicate in English but not willing to apply the main features of speaking skill.

Yet, another party of the teachers say that educational system is the number one responsible for most of the students and teachers mispronouncing most of the English words and more importantly cannot communicate successfully.

Therefore, all the above mentioned reasons are quietly all responsible for the mentioned problem but who/which is the first responsible is ensured statically here. However, according 
to the results the first responsible one is that syllabuses are not rectified frequently which again relates to the educational system. The second responsible one is mentioned as the students and the third responsible one is the teachers themselves.

Thus among all the respondents, there are only about quarter of them who agreed totally that one person/factor can be the only responsible behind the problem. That is to say, other respondents whether partially agreed or disagreed are of the opinion that educational system along with the other factors are responsible for the students are not being able to communicate successfully and they mispronounce most of the English words they had learnt at school.

All in all, the observed problem that most of the students of English in particular and graduates of secondary schools in general mispronounce most of the English words they have learnt at the schools is analytically proved through the responses of the respondents. Yet, the ambiguity of identifying the number one responsible factor is determined through the results of the statistics. Hence, it can be concluded that not only the educational system is responsible for this problem but also all the above mentioned points taking into consideration that one factor/person is more responsible than the other one.

An additional cause for the students' and teachers' incompetence is some personal, social, and linguistic factors. Such various factors are intensely considered as discouraging factors that as proved by the statistics result in affecting negatively the students' and teachers' abilities to improve their speaking skill in particular and the other skills in general.

For instance, the results of the questionnaire report that the number one discouraging factor of using/applying English stress and intonation and not being able to benefit from their linguistic values is the educational system. This indicates that neither most of the students nor most of the teachers are highly motivated by the current going on educational system; instead they are de-motivated.

The final cause for the students' and teachers' incompetence in the productive skills, mainly English stress and intonation is the absence of some of the encouraging factors that may encourage them to practice/ apply stress and intonation when they attempt to communicate in English. To illustrate this point, the results of the questionnaire maintain the absence of these factors and at the meantime declared the factor that can be the most prominent and encouraging one from amongst the other factors.

Indeed, the teachers who wanted to say that only a particular factor can certainly solve the problem and encourage the students to practice the main features of the speaking skill consider the frequent evaluation (developing teaching methods).

Thus, it can be concluded that the majority of the teachers insist on the idea that the frequent evaluation for those who try to communicate as successfully as they can by practicing and applying as many practical linguistic elements as they could. In spite of this, other factors such as English laboratories in universities, classmates, teachers, and friends can also help encouraging the students and teachers but less effectively than does the frequent evaluation. 
To all intents and purposes, these six reasons have made great and negative effects on the students' and teachers' competence in using the language productively. To put it simply, most of the students and teachers can hardly communicate successfully in English from the teachers' perspectives. In fact, the effects of the above six mentioned reasons have gradually resulted in that most of the students and teachers usually fail to communicate successfully, speak effectively, and use the language skilfully because they study nearly all the things theoretically rather than practically.

Indeed, the results proved that some of them—students have really negative attitudes; some think materialistically that such a thing is not required in any job, and some others are those who study wisely. That is to say, most of the teachers are concentrating on grammar and memorising words in the schools, too are most of the students in the English departments. In his book (2000:87) Kelly maintains that most of the teachers and learners of English find applying stress and intonation difficult, not because they are difficult but the teachers and the learners are concentrating on grammar and vocabulary and neglect/avoid to practice/apply them more than to study them theoretically.

\section{Conclusion}

The present survey-study aimed at identifying the main reason of in-service Yemeni teacher of English Language towards avoiding and neglecting the use of stress and intonation by most of the students of the faculties of Arts and Education at the University of IBB, Yemen. The main reasons for this problem were determined and discussed in terms of: 1) the chiefly neglect of English stress and intonation at the schools and more importantly at the departments of English, 2) the unawareness of the functions of applying these features and their interconnection with the other skills of the English language, 3) concentrating on the theoretical side and neglecting the practical one, 4) irresponsibility, 5) some discouraging factors such as the high difficulties of these features and the educational system, and finally 6 ) some encouraging factors such as frequent evaluation and English laboratories in the departments of English at IBB university. Furthermore, the effects of this negative practice by most of the students and teachers have been analytically determined as felt at the three levels: self-development, society development, and the country development. In effect, it can be concluded that the students as well as teachers in order to overcome the difficulties of the English stress and intonation and communicate successfully, they have to practice these features and to listen to as much English as they could. Yet, in order to practice these features they have to be encouraged. Put it differently, the students and also teachers need to be motivated and to have the means that may to a great extent help encouraging them to practice these features rather than just informing them to practice these features. Once again, it should be noticed here that the overwhelming majority of the students and teachers know it very well that the more he/she practices the more his/her skills become better. So, the following suggested solutions are based on the nature of the determined problem that the students need to be evaluated for everything they do and they want also to do only a thing/skill which they can feel its reflections and also are felt and taken into consideration by teachers, professors of English, and in any field of qualification or getting job. Frequent evaluation, however, has to be taken to high extent into consideration. Another one is that students must have English 


\section{Macrothink}

laboratories in order to be able to apply these features and at the same time feel the importance of applying such features.

\section{Acknowledgement}

The researchers would like to express their gratitude to the participating in-service Yemeni teachers of English Language from both private and public schools in IBB city, Yemen- they had really cooperated actively and effectively towards the success of this research.

\section{References}

Al-Baadani, M. (2006). Using English as a Means of Communication of Everyday Verbal Communication among the Yemeni Students of English, at the Faculty of Arts, IBB University: Problems and some Suggestions. IBB: Unpublished BA term-paper submitted to the Department of English Lang. and Liter., Faculty of Arts, The University of IBB, Yemen.

Alduais, A. M. (May, 2007). Assessing the Importance of Stress and Intonation as Supra-segmental Features of Speech and Sound-attributes to the Process of Comprehension. IBB: Unpublished term-paper submitted to the Department of Eng. Lang. and Lit., Faculty of Arts, The University of IBB, The Republic of Yemen.

Gerald, A. (1980). An Introduction to the Pronunciation of English. London: Edward Arnold. James, B. (1980). Improve your English. New Delhi: GoodWill Publishing House.

Jones, D. (1993). An Outlines of Enlgish Phonetics . New Delhi: Kalyani Publishers .

Kelly, G. (2000). How to Teach Pronunciation. Longman : Longman Press.

Roach, P. (2000). English Phonetics and Phonology . Cambridge : Cambridge University Press.

Thompson, L. (1981). Inonation Practice . Oxford: Oxford University Press.

Underwood, M. (1989). Teaching Listening . London and New York: Longman Press. 
Appendix

\section{TEACHER'S QUESTIONNAIRE}

Dear teachers,

This questionnaire is about assessing the importance of stress and intonation as supra-segmental features of speech and sound attributes to the process of comprehension. Please fill it carefully and then return it to the one who has given it to you.

I would like to assure you that all the information provided will be used only for research purposes.

Thanking you,

Please tick the following boxes for your faculty.

Faculty: Arts $\square$ Education $\square$

Please tick the box before $t$ best applies to you. Only one choice is required at a time.

1. It is argued that speaking skill can make a teacher more effective and successful in his professional life, to what extent do you agree?

Totally agree $\square$ Totally disagree $\square$ Partially agree $\square$ Partially disagree $\square$

2. It is suggested that practicing stress and intonation can make a student communicate successfully, to what extent do you agree?

Totally agree $\square$ Totally disagree $\square$ Partially agree $\square$ Partially disagree

3. Stress and intonation are the main features of speaking skill, to what extent do you agree?

Totally agree $\square$ Totally disagree $\square$ Partially agree $\square$ Partially disagree $\square$

4. Stress and intonation are so much related to each other, to what extent do you agree?

Totally agree $\square$ Totally disagree $\square$ Partially agree $\square$ Partially disagree $\square$

5. Stress and intonation belong to phonology, to what extent do you agree?

Totally agree $\square$ Totally disagree $\square$ Partially agree $\square$ Partially disagree

6. Stress and intonation are only connected with speaking skill, to what extent do you agree?

Totally agree $\square$ Totally disagree $\square$ Partially agree $\square$ Partially disagree $\square$

7. How often do you try to apply stress and intonation when you teach English?

Always $\square$ Often $\square$ Sometimes $\square$ Rarely $\square$ Never $\square$

8. How often do you try to apply stress and intonation when you communicate in English? 
Always $\square$ Often $\square$ Sometimes $\square$ Rarely $\square$ Never $\square$

9. How often do you speak English in the class?

Always $\square$ Often $\square$ Sometimes $\square$ Rarely $\square$ Never $\square$

10. Arabic sound system interference hinders the process of applying English stress and intonation?

Totally agree $\square$ Totally disagree $\square$ Partially agree $\square$ Partially disagree $\square$

11. The difficulties of English stress and intonation hinder the process of applying stress and intonation?

Totally agree $\square$ Totally disagree $\square$ Partially agree $\square \quad$ Partially disagree

12. Educational system hinders the process of applying stress and intonation?

Totally agree $\square$ Totally disagree $\square$ Partially agree $\square$ Partially disagree

13. Social situation hinders the process of applying stress and intonation?

Totally agree $\square$ Totally disagree $\square$ Partially agree $\square$ Partially disagree

14. English Laboratories in school and universities can encourage students and teachers to apply stress and intonation?

Totally agree $\square$ Totally disagree $\square$ Partially agree $\square$ Partially disagree $\square$

15. Frequent evaluation can encourage students and teachers to apply stress and intonation?

Totally agree $\square$ Totally disagree $\square$ Partially agree $\square$ Partially disagree

16. Developing teaching methods can encourage students and teachers to apply stress and intonation?

Totally agree $\square$ Totally disagree $\square$ Partially agree $\square$ Partially disagree $\square$

17. Yemeni students mispronounce most of the English words they learnt at school and at faculty level because teachers are unqualified, to what extent do you agree?

Totally agree $\square$ Totally disagree $\square$ Partially agree $\square$ Partially disagree

18. Yemeni students mispronounce most of the English words they learnt at school and at faculty level because students are not motivated, to what extent do you agree?

Totally agree $\square$ Totally disagree $\square$ Partially agree $\square$ Partially disagree $\square$

19. Yemeni students mispronounce most of the English words they learnt at school and at faculty level because the English syllabus needs to be rectified, to what extent do you agree?

Totally agree $\square$ Totally disagree $\square$ Partially agree $\square$ Partially disagree $\square$ 
20. Most teachers of English are unable to communicate successfully in English, to what extent do you agree?

Totally agree $\square$ Totally disagree $\square$ Partially agree $\square$ Partially disagree $\square$

\author{
Researchers \\ Dr. Rafiq Alshamiry \\ Ahmed M. S. Alduais
}

\title{
Copyright Disclaimer
}

Copyright reserved by the author(s).

This article is an open-access article distributed under the terms and conditions of the Creative Commons Attribution license (http://creativecommons.org/licenses/by/3.0/). 